\title{
Reflexões sobre o Processo de Urbanização e a Necessidade de Gestão Ambiental: O Caso dos Resíduos de Serviço de Saúde da Cidade de Campina Grande/PB ${ }^{1}$
}

\section{Suellen Silva Pereira ${ }^{2}$}

\section{RESUMO}

Com o processo de urbanização e industrialização vivenciado mais intensamente nos últimos 40 anos, verifica-se um aumento na demanda por atendimento médico-hospitalar e laboratorial, visto que a assistência à saúde é uma condição para obtenção de uma boa qualidade de vida. Devido ao grande volume de resíduos gerados diariamente, bem como ao caráter de contaminação comum a parte destes, faz-se necessária uma correta e adequada gestão de modo a minimizar os impactos sócio-ambientais. Assim sendo, o referido trabalho tem como finalidade refletir sobre o processo de urbanização da cidade de Campina Grande/PB e a necessidade de gestão ambiental do espaço urbano, principalmente no que se refere à crescente geração de resíduos. No presente estudo, será dada ênfase aos resíduos sólidos de serviço de saúde - RSSS gerados no município, bem como a sua gestão e impactos sócio-ambientais. Para tanto, realizou-se, como procedimentos metodológicos, o levantamento bibliográfico de modo a embasar e aprofunda as discussões propostas; bem como visitas de campo a órgãos públicos municipais, objetivando o levantamento de dados referentes aos serviços de limpeza urbana, geração e destinação dos resíduos. Verificou-se que, no município em estudo, a gestão dos RSSS foi realizada por muitos anos em desacordo com as normas e legislações vigentes, fato que corroborou para o agravamento da problemática ambiental. Desse modo, ressalta-se a necessidade de fiscalização por parte do poder público municipal, no que se refere à prestação dos serviços de gestão dos RSSS nos estabelecimento geradores, no intuito de assegurar a adequada gestão ambiental urbana do município.

Palavras-chave: Urbanização, Resíduos Sólidos de Serviço de Saúde (RSSS), Gestão Ambiental

\begin{abstract}
With the process of urbanization and industrialization experienced most intensely in the last 40 years, there is an increased demand for medical, hospital and laboratory, since health care is a condition for obtaining a good quality of life. Due to the large volume of waste generated daily, as well as the nature of contamination common to these, it is necessary a correct and proper management in order to minimize the environmental and social impacts. Thus, this work aims to reflect on the process of urbanization of the city of CampinaGrande/PB and the need for environmental management of urban space, especially in relation to the increasing waste generation. In this study, emphasis will be given to the solid waste from the health service solid wastes generated in the municipality as well as its management and environmental and social impacts. To this end, it was held, as instruments, the literature in order to base and deepens the discussion proposals, as well as field visits to municipal, aiming to survey data on urban cleaning services, generation and disposal of waste. It was found that, in the municipality under study, the management of solid wastes has been performed for many years in violation of the rules and laws in force, a fact confirmed to the aggravation of environmental problems. Thus, it emphasizes the need for inspection by the municipal government, with regard to the provision of services in property management of solid wastes generators in order to ensure appropriate environmental management of the urban municipality.
\end{abstract}

Keywords: Urbanization, Solid Waste Health Service (RSSS), Environmental Management

\footnotetext{
${ }^{1}$ Trabalho aceito para apresentação oral e publicado nos Anais do XVI Encontro Nacional dos Geógrafos - ENG em 2010. Artigo recebido em 10.02.2012. Reformulado em 21.03.2012. Recomendado para publicação em 23.04.2012 por José Ribamar Marques de Carvalho (Editor). Publicado em 24.03.2012. Organização responsável pelo periódico: UACC/UFCG.

${ }^{2}$ Doutoranda pelos Programas de Pós Graduação em Recursos Naturais (UFCG) e Geografia (UFPE), Bolsista CNPq, e-mail: suellenssp@hotmail.com
}

REUNIR - Revista de Administração, Contabilidade e Sustentabilidade - Vol. 2, no 1, p.87-103, Jan-Abr/2012. 


\section{INTRODUÇÃO}

A busca por uma boa qualidade de vida perpassa, necessariamente, por um ambiente sadio e equilibrado, bem como, pela adequada prestação de serviços de saúde, visando com isto, à promoção do bem-estar da população. Dessa forma, observa-se que, concomitantemente ao processo de urbanização evidenciado nos últimos anos, assisti-se a uma ampliação dos serviços de saúde prestados pelas diversas esferas do poder público (federal, estadual e municipal), de modo dotar a população de serviços cada vez mais especializados. Aliado a todo este processo, evidencia-se a crescente geração de resíduos de serviço de saúde proveniente dos estabelecimentos de saúde.

Os serviços de saúde, apesar de serem imprescindíveis ao desenvolvimento humano, apresentaram, nas últimas décadas, uma grande inserção de materiais descartáveis nas várias etapas dos procedimentos médicos-hospitalares, objetivando um menor grau de contaminação dos pacientes por organismos patogênicos.

Dessa forma, associado com o elevado volume de materiais descartáveis gerados diariamente nas unidades de saúde, encontrasse a ausência de um correto gerenciamento dos resíduos sólidos de saúde por parte dos profissionais que lidam diretamente com tais materiais em suas atividades cotidianas, fato que compromete a sustentabilidade do meio ambiente, tendo em vista, conforme destacado pela Pesquisa Nacional de Saneamento Básico - 2008 (IBGE, 2012a), que a maior parcela dos RSSS gerados no Brasil possuem destinação final inadequada em vazadouros a céu aberto juntamente com os demais resíduos coletados nas cidades - os chamados lixões, fato que põe em risco tanto o meio ambiente como também a saúde pública.

A população brasileira tem se concentrado, cada vez mais nas áreas urbanas e a expectativa de vida média do brasileiro vem crescendo. Estes fatores também se somam aos anteriores nas justificativas para o aumento da geração de resíduos dos serviços de saúde. Também influem na natureza e na quantidade dos resíduos gerados, fatores culturais regionais e procedimentos adotados, que dependem de fatores sazonais e até do tipo de alimentação adotado (FORMAGGIA, 1995).

Sendo Campina Grande/PB considerada uma cidade de médio porte, esta se caracteriza por ser um pólo de saúde para a população das cidades circunvizinhas que necessitam de atendimento mais especializado, em virtude da existência, de acordo com o IBGE (2012b), de 231 estabelecimentos de saúde (hospitais, clínicas, laboratórios, consultórios, dentre outros), sendo estes distribuídos em: estabelecimentos de saúde federal possuindo 01 (uma) unidade; estabelecimentos de saúde estadual com 02 (duas) unidades; estabelecimentos de saúde municipal totalizando 74 (setenta e quatro) unidades e estabelecimentos de saúde privados: com um total de 154 (cento e cinquienta e quatro) unidades, perfazendo um total de 5044 (cinco mil e quarenta e quatro leitos).

Levando em consideração esse contexto, pode-se inferir que a geração de RSSS é proporcional ao número de pessoas que buscam por atendimento médico-hospitalar, fato que reforça a importância de correto gerenciamento de tais resíduos na fonte geradora.

O referido trabalho tem como finalidade refletir sobre o processo de urbanização da cidade de Campina Grande/PB e a necessidade de gestão ambiental do espaço urbano, principalmente no que se refere à crescente geração de resíduos. No presente estudo, será dada ênfase aos resíduos sólidos de serviço de saúde - RSSS gerados no município, bem como a sua gestão e impactos sócio-ambientais.

REUNIR - Revista de Administração, Contabilidade e Sustentabilidade - Vol. 2, nº 1, p.87-103, Jan-Abr/2012. 
Afora a parte introdutória, que busca apresentar a problemática ora evidenciada ao leitor, o presente artigo se encontra estruturado em quatro momentos, a saber: o referencial teórico, que concentra parte do levantamento bibliográfico que norteou o embasamento teórico dos dados ora apresentados; a metodologia, ocasião na qual se localiza a área de estudo e as características da pesquisa; em seguida encontram-se os resultados e discussões organizados conjuntamente com base na pesquisa de campo desenvolvida; e, por fim, têm-se as considerações finais da problemática em foco.

\title{
2 REFERENCIAL TEÓRICO
}

\subsection{A relação entre população e meio ambiente: transformação do espaço e degradação ambiental}

Todo e qualquer processo de mudança, neste caso a industrialização e urbanização das cidades, gera consequiências ao meio ambiente, estas tanto positivas quanto negativas. Mas, o que se pode identificar, nesses processos de mudanças, é um imensos estragos ocasionados pela ação antrópica no planeta. Fato que, faz suscitar a necessidade de reflexão sobre as relações sociedade-natureza, para que, dessa forma, os impactos resultantes desta relação sejam minimizados.

As questões ambientais vêm se tornando temas centrais de discussões no Brasil e no Mundo. Até meados da década de 1980, falava-se muito em preservar a natureza, o meio ambiente, porém, tinha-se como foco central, preocupações voltadas para a denominada natureza intocada, ou seja, os biomas, as bacias hidrográficas, a fauna e a flora, as paisagens e os recursos naturais que compõem o ecossistema e a biodiversidade do Planeta. O meio urbano apresenta, há décadas, um intenso crescimento desordenado e acelerado, trazendo como conseqüência, principalmente nos países subdesenvolvidos, um ambiente degradado. Sobre esta questão, Corrêa (2001, p. 156), afirma que:

\begin{abstract}
A espacialidade diferencial implica que se considere o meio ambiente, de um lado, como reflexo social e, de outro, como condicionante social, isto é, reflete os processos e as características da sociedade que o criou e que ali vive, como impacta sobre o seu futuro imediato.
\end{abstract}

A história do impacto dos seres humanos sobre a natureza e os conseqüentes problemas socioambientais ocasionados ao seu próprio ambiente, está entrelaçada aos seus interesses de dominá-la, de utilizar seus conhecimentos para conquistá-la e dirigi-la segundo sua conveniência, sem se preocupar com os impactos decorrentes dessa apropriação e degradação do meio ambiente. Santos (2001, p 56) realça a crise ambiental ora vivenciada, podendo esta ser chamada de crise da modernidade:

A promessa de dominação da natureza, e do seu uso para o benefício comum da humanidade, conduziu a uma exploração excessiva e despreocupada dos recursos naturais, à catástrofe ecológica, à ameaça nuclear, à destruição da camada de ozônio, e à emergência da biotecnologia, da engenharia genética e da conseqüente conversão do corpo humano em mercadoria última.

A tomada de consciência dos riscos e da degradação ambiental em nível global ganhou impacto sobremaneira na forma de se conceber as cidades. Na medida em se constata que a maior parte dos problemas ambientais locais tem consequiências globais, as cidades passam a

REUNIR - Revista de Administração, Contabilidade e Sustentabilidade - Vol. 2, nº 1, p.87-103, Jan-Abr/2012. 
ser vinculadas a um complexo sistema dialético que envolve os pólos locais e globais. Tratasse da perspectiva de que se geralmente são as populações urbanas as principais causadoras e as primeiras a sentir os efeitos da degradação ambiental global, conseqüentemente é com base nas cidades que podem e devem ocorrer muitas das mudanças necessárias rumo a um padrão de desenvolvimento sustentável (MENEZES, 1996).

Nesta perspectiva, as cidades aparecem como um dos grandes desafios do novo século, pois, são nelas que se encontram grande parte dos problemas que levaram e levam à degradação do meio ambiente, tais como: ausência de saneamento básico; água encanada; gestão dos resíduos; poluição do ar devido aos gases provenientes das fábricas e automóveis, dentre outros. Tal fato se justifica por ser este ambiente - a cidade - um produto da ação humana sobre a natureza, que buscou sobremaneira satisfazer as suas necessidades e expectativas em detrimento do bem-estar ambiental. Nessa perspectiva, a qualidade de vida nas cidades do futuro dependerá da forma como for estabelecido o padrão de desenvolvimento urbano no presente. Fato que também é justificado por Coelho (2004, p.20), quando a autora afirma que:

Acredita-se, por exemplo, que os seres humanos, ao se concentrarem num determinado espaço físico, aceleram inexoravelmente os processos de degradação ambiental. Seguindo esta lógica, a degradação ambiental cresce na proporção em que a concentração populacional aumenta.

Tomando por base o fragmento de texto acima exposto, pode-se dizer que, a problemática ambiental nos centros urbanos, ganha maior ênfase devido ao difícil equacionamento dos impactos gerados pelo homem no seu processo de dominação do espaço urbano. Com isso, pode-se afirmar que é na cidade que se encontram os maiores impactos ambientais e estes, por sua vez, atingem um número expressivo de pessoas, tendo em vista que, atualmente a maioria da população mundial se encontra nos centros urbanos. Da mesma forma, Maglio (1999, p. 80), também ressalta a gravidade dos problemas ambientais urbanos ao colocar que:

\begin{abstract}
A busca da sustentabilidade ambiental nos centros urbanos é um dos maiores desafios ambientais deste final de século, sendo amplamente reconhecido que o acúmulo de problemas ambientais não apenas afeta a produtividade das cidades mas, ainda cobra um ônus maior das populações pobres, sobre as quais recaem os impactos desse processo, dado o precário acesso das mesmas aos serviços básicos de infra-estrutura urbana, abastecimento de água, esgotamento sanitário, coleta e disposição adequada de lixo, transportes, drenagem e outros serviços.
\end{abstract}

Neste sentido, busca-se compreender que as questões relacionadas ao meio ambiente e sua preservação devem estar integradas e correlacionadas com os processos dinâmicos urbanos. Estes, totalmente influenciados pelo modelo do sistema econômico vigente, marcado pela industrialização, alto padrões de consumo, desenvolvimento tecnológico o que reflete diretamente nos hábitos, na cultura e nos atos da população. Esse processo ocorrido de forma acelerada, desordenada, desrespeitando os elementos naturais e a dinâmica do meio ambiente reflete também em fragilidades na infra-estrutura urbana.

REUNIR - Revista de Administração, Contabilidade e Sustentabilidade - Vol. 2, nº 1, p.87-103, Jan-Abr/2012. 


\subsubsection{O meio ambiente urbano}

Para Pinheiro (1998), o processo de urbanização no Brasil é bastante significativo, na medida em que, atualmente cerca de $85 \%$ da população está concentrada nas cidades, o que representa 160.925.792 habitantes (IBGE, op. cit.). Este fato provoca diversos problemas, como exclusão em relação à moradia, e aos serviços públicos, entre outros. Particularmente por ser o capitalismo um modo de produção altamente expropriador e desigual, promovendo tanto a apropriação desmedida da natureza como a exploração dos indivíduos.

Conforme abordado anteriormente, a cidade de Campina Grande, nas últimas décadas, vem vivenciando um grande crescimento, tanto demográfico, quanto econômico, fato que vem atraindo e concentrando a população em sua área urbana, acarretando, com isso, uma transformação do seu espaço natural, que, na maioria dos casos, vem acompanhando da inexistência de planejamento e, por conseguinte, de problemas estruturais.

Dentre os problemas decorrentes da ausência de planejamento urbano e do rápido crescimento demográfico, estes aliado ao aumento do poder de compra da população, destaca-se a crescente geração de resíduos, que, por sua vez, provocam impactos tanto de ordem social, (acúmulo em vias públicas, disposição final inadequada, surgimento de uma população "catadora", dentre outros) quanto de ordem ambiental (poluição visual, proliferação de macro e micro vetores, poluição do solo, do ar, dos lençóis freáticos, etc.).

Diante da necessidade de gestão dessas substâncias, a crescente urbanização da humanidade, conforme destaca Gomes e Soares (2004), constitui uma preocupação de todos os profissionais e segmentos ligados à questão do meio ambiente, pois as cidades avançam e apresentam um crescimento rápido e, quase sempre, sem planejamento adequado, o que contribui para uma maior deterioração do espaço urbano.

Tendo em vista que a problemática dos resíduos sólidos é uma questão progressiva, na medida em que, o volume de resíduos gerados tende a aumentar ano após ano devido às mudanças nos hábitos de consumo, aumento da população, incremento da atividade industrial, dentre outros fatores. Fazem-se, necessária, medidas no sentido de atenuar os impactos oriundos da má gestão desses resíduos.

\subsection{Dilemas urbanos: a problemática dos resíduos sólidos de serviços de saúde - RSSS e a necessidade de gestão}

\subsubsection{Definição, classificação e gerenciamento}

Os resíduos de serviço de saúde são constituídos de todo e qualquer resíduos gerado dentro de uma unidade de saúde, sendo estes classificados de acordo com o tipo e o grau de contaminação. Pode-se assim dizer, que os RSSS são constituídos por uma grande variabilidade de materiais, o que lhe confere um grande risco de contaminação ambiental e humana, haja visto a inexistência, em algumas unidades, do correto gerenciamento destes.

Assim sendo, a NBR $n^{\circ} 12.808$ (ABNT, 1993), define os resíduos hospitalares (ou de serviços de saúde) como sendo os resíduos gerados pelas atividades de unidades de serviços de saúde (hospitais, ambulatórios, postos de saúde etc.). Incluem os resíduos infectantes (classe A) como culturas, vacinas vencidas, sangue e hemoderivados, tecidos, órgãos, perfurocortantes, animais contaminados, fluídos orgânicos; os resíduos especiais (classe B), rejeito radioativo, resíduos farmacêuticos e resíduos químicos; e os resíduos comuns (classe C), das áreas administrativas, das limpezas de jardins, etc.

REUNIR - Revista de Administração, Contabilidade e Sustentabilidade - Vol. 2, nº 1, p.87-103, Jan-Abr/2012. 
A RDC ANVISA n $n^{\circ}$ 306/2004 e a Resolução CONAMA n $358 / 2005$, definem como geradores de resíduos de serviços de saúde todos os serviços relacionados com o atendimento à saúde humana ou animal, inclusive os serviços de assistência domiciliar e de campo; laboratórios analíticos de produtos para a saúde; necrotérios, funerária e serviços onde se realizem atividades de embalsamamento, serviços de medicina legal, drogarias e farmácias inclusive as de manipulação; estabelecimentos de ensino e pesquisa na área da saúde, centro de controle de zoonoses; distribuidores de produtos farmacêuticos, importadores, distribuidores, produtores de materiais e controles para diagnóstico in vitro, unidades móveis de atendimento à saúde; serviços de acupuntura, serviços de tatuagem, dentre outros similares.

A classificação usualmente utilizada para os RSS é a RDC ANVISA n 306/04, que divide a geração de resíduos em cinco grupos, quais sejam:

I - GRUPO A: Resíduos com a possível presença de agentes biológicos que, por suas características de maior virulência ou concentração, podem apresentar risco de infecção; II - GRUPO B: Resíduos contendo substâncias químicas que podem apresentar risco à saúde pública ou ao meio ambiente, dependendo de suas características de inflamabilidade, corrosividade, reatividade e toxicidade; III GRUPO C: Quaisquer materiais resultantes de atividades humanas que contenham radionuclídeos em quantidades superiores aos limites de eliminação especificados nas normas da Comissão Nacional de Energia Nuclear - CNEN e para os quais a reutilização é imprópria ou não prevista; IV - GRUPO D: Resíduos que não apresentem risco biológico, químico ou radiológico à saúde ou ao meio ambiente, podendo ser equiparados aos resíduos domiciliares; V - GRUPO E: Materiais perfurocortantes ou escarificantes e todos os utensílios de vidro quebrados no laboratório e outros similares.

De acordo com a RDC $\mathrm{n}^{\circ}$ 306/2004 da ANVISA, o gerenciamento dos serviços de saúde pode ser assim definido:

Constitui-se em um conjunto de procedimentos de gestão, planejados e implementados a partir de bases científicas e técnicas, normativas e legais, com o objetivo de minimizar a produção de resíduos e proporcionar aos resíduos gerados, um encaminhamento seguro, de forma eficiente, visando à proteção dos trabalhadores, a preservação da saúde pública, dos recursos naturais e do meio ambiente.

Dessa forma, entende-se que o manuseio de tais resíduos deve ser efetuado com destreza e segurança, objetivando, dentre outros aspectos, a prevenção de acidentes e a qualidade de vida dos funcionários envolvidos nessa atividade.

Somente nos últimos anos iniciou-se uma discussão mais consistente da problemática que envolve os RSSS. Algumas prefeituras já implantaram sistemas específicos para a coleta destes resíduos, sem, entretanto, atacar o ponto mais delicado da questão: a manipulação correta dos resíduos dentro das unidades de tratamento de saúde, de forma que se possa fazer a separação de acordo com o real potencial de contaminação, daqueles que podem ser considerado resíduos comuns. Este fato se justifica, por ser a correta manipulação, como também, destinação dos RSSS de responsabilidade do gerador, ou seja, de cada estabelecimento de saúde, como observado na fala de Küemmerer (2004): A responsabilidade desses resíduos é da administração de cada unidade de saúde e deve atender as normas legais desde o momento de sua geração até o seu destino final.

REUNIR - Revista de Administração, Contabilidade e Sustentabilidade - Vol. 2, nº 1, p.87-103, Jan-Abr/2012. 
Tendo em vista que algumas unidades de saúde não se comprometem com esse gerenciamento, a municipalidade termina por assumir a responsabilidade por algumas etapas da gestão dos RSSS, como por exemplo: a coleta, o transporte e a destinação final destes.

\subsubsection{Geração e destinação final}

De acordo com o IBGE (2012a), são geradas diariamente no Brasil 259.547 toneladas de resíduos, deste total, 891 toneladas correspondem aos resíduos de serviço de saúde. Faz-se importante ressaltar que apenas 10 a $25 \%$ dos RSS gerados diariamente necessitam de cuidados especiais. Portanto, a implantação de processos de segregação dos diferentes tipos de resíduos em sua fonte, e no momento de sua geração, conduz certamente à minimização de resíduos, em especial, àqueles que requerem um tratamento prévio à disposição final. Nos resíduos onde predominam os riscos biológicos, deve-se considerar o conceito de cadeia de transmissibilidade de doenças, que envolve características do agente agressor, tais como capacidade de sobrevivência, virulência, concentração e resistência, da porta de entrada do agente às condições de defesas naturais do receptor (BRASIL, 2006).

Tomando por base pesquisas desenvolvidas por diversos autores, a quantidade média de RSSS gerados em estabelecimentos de saúde é variável, dependendo do tipo de estabelecimento, com a quantidade de material descartável utilizado no processo, e com o nível de segregação utilizado no estabelecimento, Naime et. al. (2004) cita uma média de 2,5 $\mathrm{kg} /$ paciente/dia, enquanto Claude et al (2004) em uma pesquisa realizada com 70 estabelecimentos verificou uma média de $3,0 \mathrm{~kg} / \mathrm{paciente} / \mathrm{dia}$.

Tal variação, como coloca Naime et. al. (2008), na geração de resíduos, deve-se ao fato de que, em serviços de saúde, especificamente, o grande aumento de demanda verificado desde a implantação do Sistema Único de Saúde (SUS) no Brasil, não foi acompanhado por dotações orçamentárias do mesmo porte, e, portanto, geraram uma defasagem na administração global do sistema. Além disso, a crescente utilização de materiais descartáveis como forma de controle mais eficiente das infecções e outros fatores associados, também tem contribuído decisivamente para o aumento da geração de resíduos.

A Pesquisa Nacional de Saneamento Básico/PNSB - 2008 (IBGE, 2012a) mostra que dos 5.564 municípios brasileiros, 4.469 realizam o serviço de coleta e/ou recebimento de resíduos sólidos de serviços de saúde, o que corresponde a 80,3\% do montante total. Destes, apenas 2.358 municípios alegam que dispõem de locais de disposição no solo desses resíduos, ou seja, 52,8\%. Tal estatística poderia ser animadora, não fosse à forma de disposição final desses materiais, que encontram nos vazadouros - os chamados lixões - o seu principal destino, o que pode ser comprovado na Tabela abaixo.

Tabela 1: Forma de disposição final dos RSSS no solo do município

\begin{tabular}{cccccc}
\hline & $\begin{array}{c}\text { Em vazadouro, } \\
\text { em conjunto com aterro convencional, } \\
\text { os demais } \\
\text { resíduos }\end{array}$ & $\begin{array}{c}\text { Sob controle, em } \\
\text { em conjunto com os } \\
\text { demais resíduos }\end{array}$ & $\begin{array}{c}\text { Sob controle, em } \\
\text { aterro da prefeitura } \\
\text { específico para } \\
\text { resíduos especiais }\end{array}$ & $\begin{array}{c}\text { Sob controle, em } \\
\text { aterro de terceiros } \\
\text { específico para } \\
\text { resíduos especiais }\end{array}$ & Outra \\
\hline BRASIL & $\mathbf{1 0 6 0}$ & 412 & 522 & 58 & 359 \\
\hline PARAÍBA & $\mathbf{6 1}$ & 15 & 5 & 2 & 24 \\
\hline
\end{tabular}

Fonte: IBGE (2012a - adaptada) - grifo nosso.

De acordo com os dados do PNSB - 2008 (IBGE, op. cit.), demonstrados na Tabela 1, observa-se que a destinação em vazadouros, correspondem a prática de $44,95 \%$ dos

REUNIR - Revista de Administração, Contabilidade e Sustentabilidade - Vol. 2, nº 1, p.87-103, Jan-Abr/2012. 
municípios brasileiros que realizam a coleta dos RSSS, o que ressalta a necessidade de políticas públicas neste setor, de modo a minimizar os danos provenientes da ausência de gestão desses materiais.

No que se refere aos dados do Estado da Paraíba, do total de 223 municípios, 129 destes realizam a coleta dos RSSS. Quanto à destinação, 103 municípios possuem, em seu território, locais para a disposição final dos resíduos, sendo grande parte destes $(59,2 \%)$ encaminhados para os lixões municipais, como destacado na Tabela 2. Quanto ao tratamento, apenas 73 municípios informaram possuir algum tipo de tratamento dos RSSS antes destes serem dispostos, o alarmante é que 47 localidades $(64,4 \%)$, realizam tais serviços através da queima dos resíduos a céu aberto, comprometendo seriamente a qualidade ambiental da região em que esta é realizada. Fato que reforça e ressalta a problemática em nível local e nacional.

\section{METODOLOGIA}

\subsection{Localização Geográfica da Área de Pesquisa}

Situado no semiárido nordestino, o município de Campina Grande está localizado na Microrregião de Campina Grande e na Mesorregião do Agreste Paraibano, estando localizada na província da Borborema, cuja estrutura geológica é cristalina. A Figura 1 apresenta a localização do município em estudo.

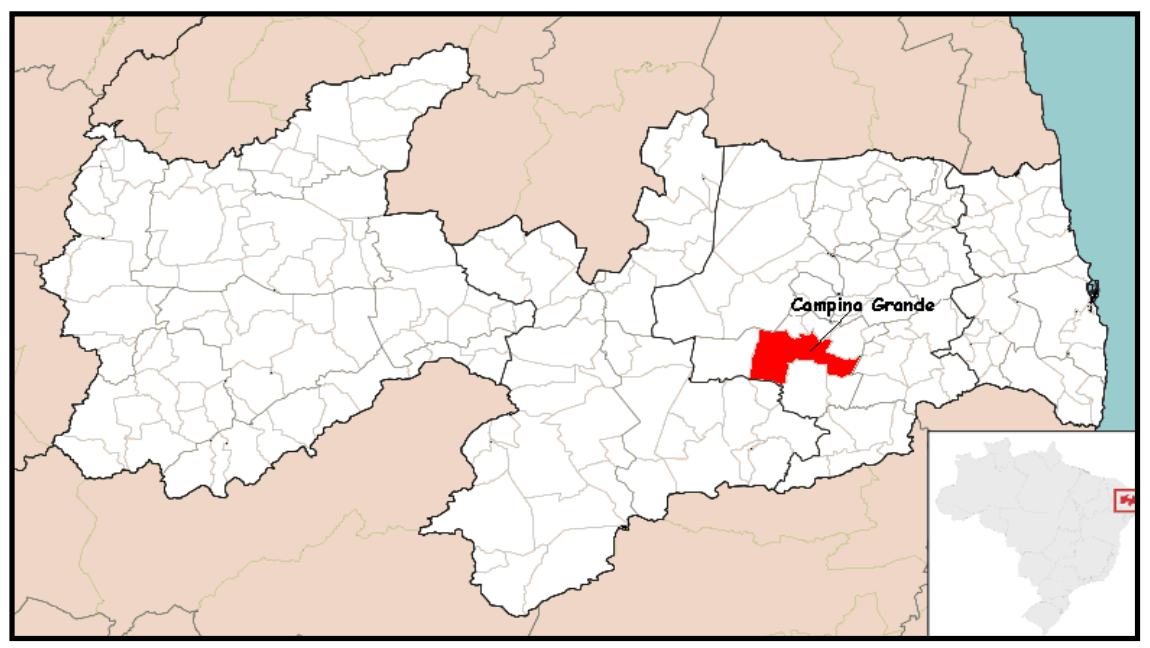

Figura 1: Localização do município de Campina Grande no Estado da Paraíba

Fonte: Google Maps (http://maps.google.com.br/maps?hl=pt-BR\&tab=ll - Adaptado pela autora, 2012)

Distante $120 \mathrm{Km}$ da capital João Pessoa, a cidade de Campina Grande está situada entre a altitude de 550 à $558 \mathrm{~m}$ e possui as seguintes coordenadas geográficas: Latitude de $7^{\circ} 13^{\prime} 50^{\prime}$ ' Sul e Longitude de $35^{\circ} 52^{\prime}$ '52” W.GR.

\subsection{Procedimentos Metodológicos}

Para realização do presente artigo recorreu-se ao método analítico-descritivo, visto que este objetiva analisar e refletir sobre o processo de urbanização e a problemática dos resíduos de serviços de saúde, bem como descrever o processo de gestão de tais resíduos no município de Campina Grande/PB.

REUNIR - Revista de Administração, Contabilidade e Sustentabilidade - Vol. 2, nº 1, p.87-103, Jan-Abr/2012. 
Como estratégia metodológica, foi feito um levantamento bibliográfico de algumas publicações de maior relevância no que concerne ao tema e, a partir do mesmo, foi feita uma análise crítica, de modo a alcançar os objetivos propostos; bem como a Pesquisa de Campo, com visita a órgãos públicos municipais, utilizando como instrumento para a coleta de dados o questionário semi-estruturado, sendo este aplicado junto ao responsável pelo setor de limpeza urbana municipal, da Secretária de Obras e Serviços Urbanos/SOSUR, objetivando o levantamento de dados referentes aos serviços de limpeza urbana, coleta e disposição final dos resíduos sólidos de serviços de saúde.

Os dados foram analisados qualitativamente, haja visto que o objetivo maior do presente estudo refere-se aos fatores qualitativos que envolvem a temática abordada por acreditar na importância destas para o enriquecimento e entendimento da necessidade de gestão do ambiente urbano de Campina Grande/PB, buscando, de posse dos dados, traçar um panorama do gerenciamento dos RSSS gerados na cidade em questão.

\section{RESULTADOS E DISCUSSÕES}

\subsection{Urbanização e Meio Ambiente: a evolução urbana da cidade de Campina Grande/PB e a degradação ambiental}

Tendo em vista que um dos fatores que influenciam a geração dos resíduos são os processos de industrialização e urbanização de uma cidade, necessário se faz, portanto, realizar um retrospecto da evolução urbana da cidade em estudo para que, dessa forma, se possa obter subsídios que leve a uma compreensão totalizante da problemática ora evidenciada, qual seja, a crescente geração de resíduos, com ênfase para os resíduos sólidos de serviço de saúde - RSSS.

\subsubsection{Aspectos históricos, demográficos e socioeconômicos}

A cidade de Campina Grande é uma das mais antigas cidades do Estado da Paraíba. Teve seu núcleo inicial em aldeamento de índios Ariús, fixados pelo Capitão-Mor Teodósio de Oliveira Ledo, em 1697. O aldeamento logo se converteu em próspero povoado em virtude da sua privilegiada situação geográfica. Em 1790 o povoado torna-se vila, sob a denominação de Vila Nova da Rainha, através de edital publicado em 06 de abril daquele ano, em conformidade à Carta Régia de 22 de julho de 1766.

Campina Grande conquista sua independência política em 11 de outubro de 1864, pela Lei Provincial $\mathrm{N}^{\circ} 137$, elevando-se à categoria de cidade. Em 1888, Campina Grande foi considerada a mais populosa e próspera localidade do interior paraibano, com cerca de 4.000 habitantes. Em 1892, possuía aproximadamente 400 prédios; no final do século, cerca de 500, continuando seu crescimento vagaroso até atingir 731 prédios em 1907, quando o primeiro trem chega.

Apesar do desenvolvimento econômico apresentado pela cidade, principalmente em 1907, com a chegada da estrada de ferro, dando a mesma a posição de império comercial, o crescimento populacional até a primeira metade do século XX foi lento e a expansão urbana deu-se de maneira espontânea, ou seja, não houve um disciplinamento da urbanização.

Em 1920, com uma população de 70.806 habitantes, é inaugurada a iluminação pública das principais áreas da cidade. Em 1936, Campina Grande já era a principal cidade do interior

REUNIR - Revista de Administração, Contabilidade e Sustentabilidade - Vol. 2, no 1, p.87-103, Jan-Abr/2012. 
nordestino, contando com uma população de cerca de 100.000 habitantes (GURJÃO et al, 2000). Sendo esta expansão percebida até os dias atuais.

De acordo com o último Censo Demográfico, realizado no ano de 2010, a sua população é de 385.213 habitantes $^{3}$, estando esta, em sua maioria $(95,33 \%)$, localizada na zona urbana da cidade, sendo o segundo município em população do Estado. A evolução urbana da cidade pode ser observada na Tabela 2.

Tabela 2: Demografia da População de Campina Grande/PB.

\begin{tabular}{lrrrrr}
\hline & $\mathbf{1 9 7 0}$ & $\mathbf{1 9 8 0}$ & $\mathbf{1 9 9 1}$ & $\mathbf{2 0 0 0}$ & $\mathbf{2 0 1 0}$ \\
\hline População Total & $\mathbf{1 9 5 . 3 0 3 . 0 0}$ & $\mathbf{2 4 7 . 8 2 0 . 0 0}$ & $\mathbf{3 2 6 . 3 0 7 . 0 0}$ & $\mathbf{3 5 5 . 3 3 1 . 0 0}$ & $\mathbf{3 8 5 . 2 1 3 . 0 0}$ \\
Masculina & 91.040 .00 & 116.000 .00 & 152.930 .00 & 168.236 .00 & 182.205 .00 \\
Feminina & 104.263 .00 & 131.820 .00 & 173.377 .00 & 187.095 .00 & 203.008 .00 \\
Urbana & 167.335 .00 & 228.171 .00 & 307.468 .00 & 337.484 .00 & 367.209 .00 \\
Rural & 27.968 .00 & 19.649 .00 & 18.839 .00 & 17.847 .00 & 18.004 .00 \\
Taxa de Urbanização & $\mathbf{8 5 , 6 8 \%}$ & $\mathbf{9 2 , 0 7 \%}$ & $\mathbf{9 4 , 2 3 \%}$ & $\mathbf{9 4 , 9 8 \%}$ & $\mathbf{9 5 . 3 3 \%}$ \\
\hline
\end{tabular}

Fonte: (IBGE, 2012d) (grifo nosso).

Segundo a hierarquia da rede urbana brasileira, Campina Grande se classifica como Centro Submetropolitano ${ }^{4}$, ou seja, a referida cidade, juntamente com a capital João Pessoa exerce uma grande influência nos municípios vizinhos, esta, tanto de caráter econômico, cultural, educacional e social. A economia da cidade é baseada na indústria, comércio e no turismo de eventos e se destaca das demais regiões do Estado pela sua diversidade de atividades culturais, esportivas e especialmente pela boa estrutura educacional.

Quanto aos aspectos sociais, a cidade enfrenta as mesmas dificuldades das demais cidades em relação às áreas de economia, saúde, educação básica e moradia. É bem verdade que, quando se fala na prestação de serviços como energia elétrica, saneamento básico e abastecimento de água, a cidade apresenta bons indicadores, sendo Campina Grande, de acordo com o Censo Demográfico do ano de 2010, eletrificada em 99,6\% de suas moradias, o que totaliza 111.400 domicílios; com $83,6 \%$ de serviços de saneamento total adequado, $15,0 \%$ de serviços semi-adequados e $1,4 \%$ de serviços considerados inadequados quanto ao saneamento; no que se refere à rede de abastecimento de água, 97,7\% dos domicílios contam com acesso a água pela rede geral de abastecimento (IBGE, 2012c), sendo este recurso idade proveniente do Açude Epitácio Pessoa (Boqueirão), possuindo uma capacidade total de 418.088.514 $\mathrm{m}^{3}$ de água.

\subsubsection{Os resíduos de serviço de saúde em Campina Grande/PB}

Os serviços de coleta e destinação dos resíduos gerados na cidade em estudo são realizados pela Secretaria Municipal de Obras e Serviços Urbanos - SOSUR, 03 (três) vezes

\footnotetext{
${ }^{3}$ Segundo estimativas do Instituto Brasileiro de Geografia e Estatística - IBGE, a população estimada da cidade de Campina Grande para o ano de 2011 foi de 387.644 habitantes, o que corresponde, em termos percentuais, a um acréscimo de $0,62 \%$ (IBGE, 2012b).

${ }^{4}$ Estudo realizado pelo Instituto Brasileiro de Geografia e Estatística - IBGE, em 1987 e intitulado Regiões de Influência das Cidades, apresenta uma hierarquização das cidades de acordo com a capacidade de influência e intensidade de relações econômicas e populacionais ao seu entorno, sendo esta hierarquia composta por seis níveis: Centros Metropolitanos, Centros Submetropolitanos, Capitais Regionais, Centros de Zonas e Municípios Subordinados (apud SILVA JÚNIOR, 2009).
}

REUNIR - Revista de Administração, Contabilidade e Sustentabilidade - Vol. 2, nº 1, p.87-103, Jan-Abr/2012. 
por semana, sendo estes em dias alternados, com exceção do centro comercial, que é realizado diariamente sempre no terceiro turno de trabalho - à noite.

No caso específico da cidade em pauta, a Secretaria de Obras e Serviços Urbanos (SOSUR) realiza $10 \%$ da coleta de resíduos da cidade. Os $90 \%$ restantes são coletados pela empresa terceirizada, tal serviço vem sendo prestado à municipalidade desde o ano de 1997, sendo atualmente executados pelas empresas LIDER e Montreal, os quais são gerenciados e fiscalizados pela SOSUR.

A SOSUR está estruturada em diversas diretorias e chefias, cada uma delas com suas respectivas funções. Tal organização visa um melhor desempenho de suas atividades no que se refere à limpeza urbana da cidade, sendo a SOSUR responsável pela prestação dos seguintes serviços: limpeza urbana; remoção de entulhos; coleta de resíduos; disposição final dos resíduos, dentre outros.

As receitas orçamentárias da cidade de Campina Grande/PB são da ordem de R\$ 424.182.801,26 milhões, cuja fonte de recursos é proveniente de repasse federal, estadual e municipal. Na legislação municipal, cabe ao município a execução dos serviços de coleta, transporte e destinação final dos resíduos coletados (VIANA, 2002).

$\mathrm{Na}$ cidade em estudo, a taxa pela prestação do serviço de limpeza urbana e/ou coleta dos resíduos é cobrada junto ao Imposto Predial Territorial Urbano - IPTU, que é pago anualmente. No ano de 2009 a arrecadação com o IPTU totalizou R $\$ 4.374 .218,73^{6}$ milhões.

De acordo com o Relatório Mensal da Diretoria de Limpeza Urbana (DULUR) da Secretaria de Obras e Serviços Urbanos (SOSUR) de Campina Grande/PB, são geradas mensalmente 12.605,33 toneladas de resíduos, onde, deste total, 32,88 toneladas são de Resíduos Sólidos de Serviço de Saúde, o que corresponde a menos de 1\% de RSSS do montante total, estando este percentual dentro dos padrões observados em diversas pesquisas já realizadas em âmbito nacional, fato este destacado em Mota et. al. (2004).

Tal valor poderia passar despercebido, se não fosse o potencial de organismos patogênicos existente nesse tipo de resíduo, fato que contribui para a contaminação da população e do meio ambiente, quando desconsiderado o processo de gestão estabelecido, principalmente, pela RDC $n^{\circ} 306$ da ANVISA e Resolução no 358 do CONAMA.

Em visita realizada na SOSUR no primeiro trimestre do ano de 2009, quando da aplicação de questionário semi-estruturado junto ao responsável pelo setor de limpeza urbana, pode-se constatar que os RSSS coletados no município estavam sendo dispostos no lixão municipal ${ }^{7}$, ambiente localizado na Alça Sudoeste, BR $230 \mathrm{Km}$, distante cerca de $8 \mathrm{~km}$ do centro da cidade, ocupando uma área de $35 \mathrm{Km}^{2}$. Tal constatação também foi evidenciada nos levantamentos bibliográficos realizados em artigos publicados em periódicos e anais de eventos contendo pesquisas versando sobre o tema conforme Braz et. al. (2006), Vasconcelos et. al. (2006). Ainda de acordo com informações prestadas pelo diretor de limpeza urbana municipal, a Empresa LIDER S/A, empresa terceirizada que presta serviços de limpeza urbana na cidade, estava tentando, na época, obter autorização ambiental junto a

\footnotetext{
${ }^{5}$ Consulta realizada em: 19 de março de 2012 no site: www.ibge.gov.br/cidadesat/topwindow.htm?1. Dados referentes ao ano de 2009.

${ }^{6}$ Idem.

${ }^{7}$ Faz-se oportuno registrar o encerramento das atividades de disposição final dos resíduos gerados na cidade de Campina Grande/PB no lixão municipal, no início do ano de 2012, sendo estes conduzidos para um aterro consorciado construído na cidade de Puxinanã. Apesar de os resíduos não estarem mais sendo depositados no lixão, isto não significa o seu fim, haja visto a existência de grande quantidade de resíduos depositadas naquele local, bem como a necessidade de recuperação da referida área, o que pode levar décadas, visto que desde o ano de 1993 os resíduos estão sendo ali destinados contribuído para a contaminação ambiental.
}

REUNIR - Revista de Administração, Contabilidade e Sustentabilidade - Vol. 2, nº 1, p.87-103, Jan-Abr/2012. 
Superintendência de Administração do Meio Ambiente e dos Recursos Hídricos da Paraíba SUDEMA, órgão responsável pelas deliberações referentes à gestão ambiental no Estado a Paraíba, visando o encaminhamento desses resíduos para a incineração, sendo esta licença concedida no ano de 2009.

A Figura 2 apresenta o ambiente do lixão municipal, bem como a presença dos catadores no exercício da coleta dos recicláveis ali presentes. Alerta-se para a ausência do uso de Equipamentos de Proteção Individual - EPI'S por parte dos catadores, corroborando para uma maior susceptibilidade dos riscos inerente a atividade por estes desenvolvida, haja visto a diversidade, bem como a inexistência de tratamento dos resíduos antes destes serem dispostos naquele ambiente.

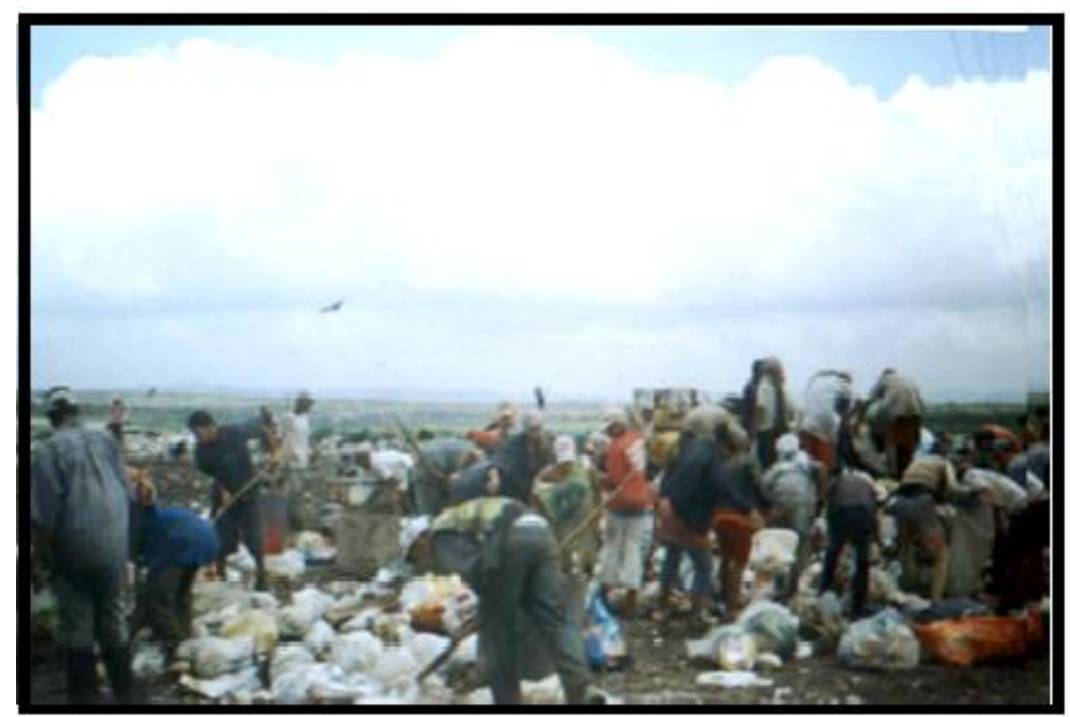

Figura 2: Ambiente do lixão municipal coma presença de catadores na atividade de segregação dos resíduos recicláveis no lixão de Campina Grande/PB. Fonte: Pereira e Melo (2008c).

Em visita realizada no ambiente do lixão municipal de Campina Grande/PB, é comum encontrar catadores que, quando argüidos, relatam a presença constante de materiais provenientes de unidade de saúde que são descartados naquele local. De acordo com o depoimento de alguns catadores, estes afirmam já terem sofrido pequenos acidentes devido à presença de materiais perfurocortantes, como as agulhas, por exemplo, podendo este material ser um agente potencial de contaminação. Tal constatação é reforçada por Bidone e Povinelli (1999) ao destacarem que na maioria das vezes os resíduos sólidos de serviços de saúde ficam ao alcance de catadores, elevando a possibilidade de contaminação por doenças infectocontagiosas.

Neste contexto, pode-se dizer que a destinação final dos resíduos sólidos de serviço de saúde, durante o período em que estes foram dispostos no lixão de Campina Grande/PB, corroborou para o processo de degradação ambiental daquele espaço, bem como potencializou a probabilidade de danos e/ou agravos decorrentes do manuseio desses dejetos, haja vista a existência de grande quantidade de material descartável presente nesses materiais (fato que termina por atrair os catadores em busca de tais resíduos), assim como o desconhecimento e/ou descaso da população catadora para com os riscos decorrentes da manipulação dos RSSS sem a utilização de equipamentos de proteção adequados.

REUNIR - Revista de Administração, Contabilidade e Sustentabilidade - Vol. 2, no 1, p.87-103, Jan-Abr/2012. 
Os RSSS devem ser acondicionados em sacos específicos conforme regulamentação da NRB 9190 e 9191/1993 da Associação Brasileira de Normas e Técnicas - ABNT, as quais estabelecem a especificação e classificação, respectivamente, dos sacos plásticos para acondicionamento dos resíduos. O que de fato nem sempre acontece, haja vista, por exemplo, a falta dos materiais específicos, bem como o desconhecimento por parte de funcionários das fontes geradoras, que por vezes promovem a segregação incorreta desses materiais, podendo esta prática vir a comprometer e contaminar os resíduos comuns, acarretando em danos ao meio ambiente e a saúde pública, conforme demonstrado na Figura que se segue.

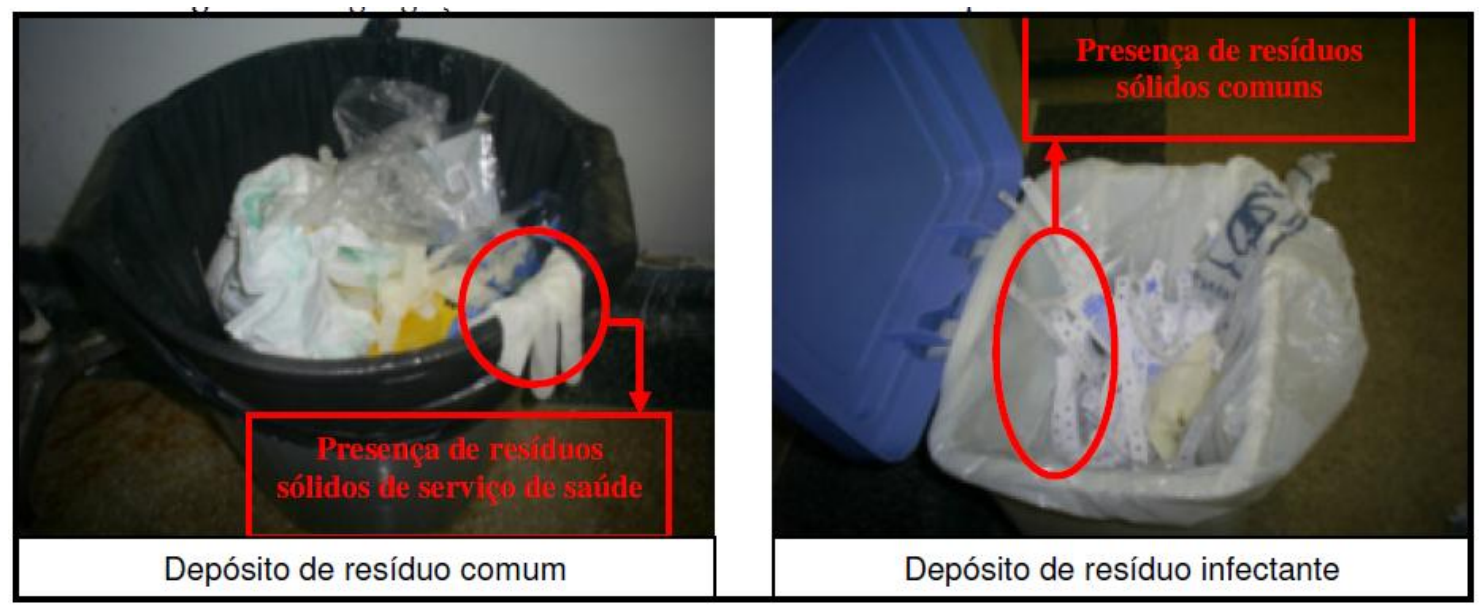

Figura 3: Segregação incorreta dos resíduos gerados em uma unidade hospitalar da cidade de Campina Grande, PB.

Fonte: Pereira, et. al. (2010).

Atualmente, a empresa LIDER S/A presta os serviços de coleta, transporte e destinação final dos Resíduos Sólidos de Serviços de Saúde - RSSS do município. Para realização desse serviço dispõe de um incinerador com capacidade de $16 \mathrm{t} / \mathrm{mês}$. A capacidade instalada é de $50 \mathrm{~kg} / \mathrm{h}$ e o custo de incineração é de $\mathrm{R} \$ 2.000,00 / \mathrm{t}$ incluindo a coleta, transporte e a queima desses resíduos. Para os demais estabelecimentos geradores de RSSS devem obedecer à resolução do CONAMA No 283/2001 que determinam atenção especial para os resíduos dos grupos $\mathrm{A}, \mathrm{B}, \mathrm{C}$ e $\mathrm{D}$ que atualmente são coletados, transportados e incinerados pela empresa SERQUIP - Tratamento de Resíduos (CIRNE, 2010). Registra-se que este tipo de destinação é reservado aos resíduos infectantes, passíveis de contaminação devido à presença de organismos patogênicos.

Faz-se oportuno informar que, apesar de os resíduos sólidos de serviços de saúde do município em foco não estarem mais sendo dispostos no lixão municipal desde o ano de 2009, estes causaram grande pressão naquele ambiente decorrente do período em que ali foram destinados, haja vista que estes antes de serem dispostos não sofriam nenhum tratamento objetivando minimizar a presença de agentes patogênicos transmissores de doenças. Outro agravante refere-se, como apontado anteriormente, a existência de materiais perfurocortantes como as agulhas que, por vezes não recebem o descarte adequado e são segregadas juntamente com as seringas, promovendo riscos de acidente quando manipulados.

Neste contexto, ressalta-se a iniciativa do poder público municipal no sentido de promover a destinação adequada dos resíduos sólidos de serviços de saúde, ao tempo que alerta-se para a necessidade de capacitação dos funcionários, por parte dos estabelecimentos geradores, para a correta manipulação, segregação, descarte e acondicionamento dos RSSS,

REUNIR - Revista de Administração, Contabilidade e Sustentabilidade - Vol. 2, no 1, p.87-103, Jan-Abr/2012. 
de modo a não comprometer o gerenciamento destes, tampouco inviabilizar o correto processamento através da incineração, devido a alevação dos custos referentes a prestação de tais serviços, visto que, quando segregados de forma inadequada, corre-se o risco de elevar o volume dos materiais a serem incinerados devido a presença de resíduos comuns, considerados não infectantes e, portanto, carecendo estes de outra forma de destinação conforme preconizado nas normas e legislações vigentes.

\section{CONSIDERAÇÕES FINAIS}

Diante do exposto, observou-se que a gestão adequada dos resíduos sólidos de serviços de saúde - RSSS é uma deficiência evidenciada em todo o território nacional, onde, por vezes, estes materiais não recebem tratamento e destinação final adequada e diferenciada conforme sua natureza, tendo por destino final o mesmo local utilizado para descarte dos demais resíduos urbanos (BRILHANTE; CALDAS, 1999).

A destinação incorreta dos RSSS pode ocasionar, ainda, a contaminação do meio ambiente, fato que pode ser reforçado por Naime et al (2006, p. 117), ao afirmar que a geração de resíduos em geral, e seu posterior abandono no meio ambiente podem ocasionar grandes problemas ambientais, que de um lado podem estar relacionados aos fatores de proliferação de agentes contaminantes e de outro com o fato de que o aumento de resíduos provavelmente implica no consumo de matérias-primas, atualmente escassas na natureza.

Diante das informações expostas no corpo do presente artigo, verificou-se que durante um longo período os resíduos sólidos de serviços de saúde da cidade de Campina Grande/PB eram destinados para o ambiente do lixão municipal, local de disposição final dos resíduos coletados na cidade em estudo, sendo estes serviços (coleta e destinação) prestados pela Prefeitura Municipal de Campina Grande/PB, situação que ia de encontro aos padrões que se é exigido por Normas e Legislações que regulamentam o correto gerenciamento dos RSSS.

Apesar de atualmente os RSSS gerados no município terem uma destinação considerada adequada, através da incineração, haja vista o alto grau de contaminação decorrentes da patogenicidade, virulência e infectabilidade presentes em alguns tipos de resíduos gerados nas unidades de saúde, podendo estes virem a comprometer a qualidade ambiental, bem como a saúde da população quando dispostos em locais inapropriados. Ressalta-se que nem todos os resíduos gerados na unidade de saúde são considerados infectantes, sendo estes constituídos por resíduos comuns, assim como também é grande a presença dos resíduos recicláveis, estes só passam a ser considerados infectantes quando segregados de forma incorreta ainda na fonte geradora.

Neste sentido, ressalta-se a necessidade de uma maior fiscalização por parte do poder público municipal, assim como de órgãos ambientais, como a SUDEMA, de modo a verificar se as normas e legislações vigentes para a gestão dos RSSS estão sendo realmente cumpridas nos estabelecimentos de saúde, bem como verificar a existência do Plano de Gerenciamento de Resíduos de Serviço de Saúde - PGRSS, sendo este obrigatório em todo e qualquer estabelecimento de gere este tipo de resíduo, o que na prática não é muito observado, fato que comprometer todo o processo de gerenciamento, a começar pela segregação, culminando com a destinação final.

Outrossim, chama-se a atenção, para a inexistência de leis municipais que normatizem o adequado gerenciamento dos resíduos sólidos de serviços de saúde gerados na cidade de Campina Grande/PB, de modo a minimizar os impactos negativos decorrentes da

REUNIR - Revista de Administração, Contabilidade e Sustentabilidade - Vol. 2, no 1, p.87-103, Jan-Abr/2012. 
manipulação inadequada destes, reduzindo, por conseguinte, os riscos a saúde pública e ao meio ambiente, sem comprometer a gestão ambiental urbana da cidade em foco.

\section{REFERÊNCIAS}

ABNT, Associação Brasileira de Normas Técnicas. NBR 9190. Sacos plásticos para acondicionamento de lixo - Especificação. Rio de Janeiro, 1993.

Associação Brasileira de Normas Técnicas. NBR 9191. Sacos plásticos para acondicionamento de lixo - Classificação. Rio de Janeiro, 1993.

. Associação Brasileira de Normas Técnicas. NBR 12808. Resíduos de Serviços de Saúde: Classificação. Rio de Janeiro de 1993.

ANVISA, Agência Nacional de Vigilância Sanitária, Resolução RDC $N^{o} 306$, de 07 de dezembro de 2004.

BRASIL, Ministério da Saúde. Agência Nacional de Vigilância Sanitária. Manual de gerenciamento de resíduos de serviços de saúde. Brasília: Ministério da Saúde, 2006.

BRAZ, S. C. S., et. al. A responsabilidade das clínicas e hospitais pelos resíduos produzidos: uma questão de saúde pública. In: Anais... da 58 REUNIÃO ANUAL DA SBPC Florianópolis, SC - Julho/2006.

BEZERRA, V. P. Gerenciamento dos resíduos sólidos produzidos por serviços de um hospital-escola. Ações educativas. Dissertação de mestrado em Enfermagem de Saúde Pública. Universidade Federal da Paraíba, 1995.

BIDONE, F. R. A.; POVINELli, J. Conceitos básicos de resíduos sólidos. São Carlos. Ed. EESC/USP, p. 120, 1999.

BRILHANTE, O. M.; CALDAS, L. A. Gestão e avaliação de risco em saúde ambiental. Rio de Janeiro. Ed. Fiocruz, p. 155, 1999.

CIRNE, L. E. da M. R. A coleta seletiva como subsídio à criação de um plano de gestão integrada de resíduos sólidos (PGIRS) em Campina Grande/PB: implicações ambientais, econômicas e sociais. Tese de Doutorado em Recursos Naturais, Universidade Federal de Campina Grande/PB, Campina Grande, 2010.

CLAUDE, M. et. al. O gerenciamento dos resíduos dos serviços de saúde de uma amostra de hospitais nacionais. Rio de Janeiro: FGV pesquisa - Núcleo de Pesquisas e Publicações NPP, Relatório Final, setembro de 2004.

COELHO, M. C. N. Impactos Ambientais em Áreas Urbanas - teorias, conceitos e métodos de pesquisa. In: GUERRA, A.J.T. \& CUNHA, S.B. (Orgs.). Impactos Ambientais Urbanos no Brasil. 2 ed. Rio de Janeiro: Bertrand Brasil, 2004, p.19-45.

REUNIR - Revista de Administração, Contabilidade e Sustentabilidade - Vol. 2, no 1, p.87-103, Jan-Abr/2012. 
CONFORTIN, A. C. Estudo dos resíduos de serviço de saúde do hospital do Oeste/SC. Dissertação de Mestrado em Engenharia de Produção da Universidade Federal de Santa Catarina - Florianópolis, 2001.

CONAMA. Conselho Nacional de Meio Ambiente. Resolução no 358 de 29 de abril de 2005. Dispõe sobre o tratamento e a disposição final dos resíduos de serviços de saúde e dá outras providências.

GOMES, M. A. S; SOARES, B. R. Reflexões Sobre Qualidade Ambiental Urbana. Revista Estudos Geográficos - Unesp. Rio Claro, SP. Jul-dez 2004.

GURJÃO, E. de Q. (Org.) et. al. Imagens Multifacetadas da História de Campina Grande. Campina Grande/PB: Copyright, 2000, 189p.

CORRÊA, R. L. Trajetórias Geográficas. 2 ed. Rio de Janeiro: Bertrand Brasil, 2001.

FORMAGGIA, D. M. E. Resíduos de Serviços de Saúde. In: Gerenciamento de Resíduos sólidos de Serviços de Saúde. São Paulo: CETESB; 1995. p. 3-13.

IBGE, Instituto Brasileiro de Geografia e Estatística. Pesquisa Nacional de Saneamento Básico - 2008. Disponível em: <http://www.ibge.gov.br/home/estatistica/populacao/condicaodevida/pnsb2008/defaulttabzip_ man_res_sol.shtm>. Acesso em 19 de março de 2012a. Link

Instituto Brasileiro de Geografia e Estatística. Cidades. Disponível em: <http://www.ibge.gov.br/>. Acesso em 19 de março de 2012b. Link

. Instituto Brasileiro de Geografia e Estatística. Censo Demográfico - 2010. Disponível em: < http://www.ibge.gov.br/>. Acesso: 19 de março de 2012c. Link

Disponível

Instituto Brasileiro de Geografia e Estatística. Banco de Dados Agregados - SIDRA.

<http://www.sidra.ibge.gov.br/bda/tabela/listabl.asp?z=t\&o=25\&i=P\&c=206>. Acesso em: Acesso: 19 de março de 2012d. Link

KÜEMMERER, K. Effluent Management for Hospitals. In: Conference in the $2^{\circ}$ International Symposium on Residue Management in Universities: UFSM, 2., Book of abstracts. Santa Maria: UFSM, 2004, p.29.

MAGLIO, I. C. Cidades Sustentáveis: preservação, controle e mitigação de impactos ambientais em áreas urbanas. In: PHILIPPI, JR. A., MAGLIO, I.C., COIMBRA, J.A.A. Municípios e Meio Ambiente: perspectivas para a municipalização da gestão ambiental no Brasil. São Paulo: ANAMA, 1999. p. 80-85.

MENEZES, C. L. Desenvolvimento Urbano e Meio Ambiente: A Experiência de Curitiba. Campinas, SP: Papirus, 1996. p.207. 
MOTA, S. M. et. al. Impactos dos resíduos de serviços de saúde sobre o homem e o meio ambiente. In: Arquivos em Odontologia, Belo Horizonte, v.40, v.2, abr./jun. 2004, p. 159-174.

NAIME, R., et. al. Uma abordagem sobre a gestão de resíduos de saúde. Revista Espaço para a Saúde, Londrima, v. 5, n. 2, p. 17-27, jun. 2004.

. Diagnóstico do Sistema de Gestão dos Resíduos Sólidos do Hospital de Clínicas de Porto Alegre. Revista UNICiências, v. 10, p. 103-44, 2006.

Avaliação do Sistema de Gestão dos Resíduos Sólidos do Hospital de Clínicas de Porto Alegre. Revista Espaço para a Saúde, v.9, n.1, p.1-17, Dez. 2008.

PEREIRA, S. S.; MELO, J. B. Valoração socioeconômica dos resíduos sólidos urbanos da cidade de Campina Grande/PB. Revista AIDIS de Ingeniería y Ciencias Ambientales: Investigacíon, desarollo y práctica. Vol. 1, n. 4. Ano 2008.

PEREIRA, S. S., et. al. Resíduos de serviço de saúde em um hospital de Campina Grande/PB: gestão e percepção ambiental. In: Revista Brasileira de Gestão e Desenvolvimento Regional, v. 6, n. 3, Taubaté, SP, p. 255-286, set-dez/2010.

PINHEIRO, A. C. O Espaço Urbano e a Questão Ambiental. Revista Paranaense de Geografia. No 03. Curitiba, p. 58-69, 1998.

SANTOS, B. de S. A crítica da razão indolente: contra o desperdício da experiência. 3 ed. São Paulo: Cortez, 2001.

SILVA JUNIOR, F. G. da. Campina Grande: Desenvolvimento Histórico no século XX .In: OLIVEIRA, R. V. de. Campina Grande em debate: a condição urbana na periferia pela lente do trabalho e das políticas publicas. Campina Grande: EDUEPB; EDUFCG, 2009. p. 11-34.

VASCONCELOS, E. A. de; et. al. Diagnóstico do problema dos resíduos sólidos hospitalares: o caso de Campina Grande-PB. HYGEIA, Revista Brasileira de Geografia Médica e da Saúde, dezembro de 2006, p. 28-34.

VIANA, V. B. Diagnóstico sócio-ambiental do lixão da cidade de Campina Grande-PB. Dissertação de Mestrado em Desenvolvimento e Meio Ambiente - PRODEMA da Universidade Estadual da Paraíba, Campina Grande, 2002. 